\title{
Opinion of policy makers regarding the need of 'global accreditation' of undergraduate medical education in Bangladesh
}

\author{
Brig. Gen. Suraya Begum ', Professor Dr. Md. Humayun Kabir Talukder ${ }^{2}$
}

\begin{abstract}
Accreditation of undergraduate medical education has been practicing worldwide in developed and developing countries. Fundamental ideas of this program is to ensure incorporation of ongoing global developments, evidence based scientific study and maintenance of minimum basic standard in education for population health and safety. WHO and WFME have been addressing for global standards in medical education and global accreditation of medical institutes for long time. Worldwide many countries have been responded to this call of global accreditation of medical colleges and medical education with their own context and experiencing benefits
\end{abstract}

This exploratory cross sectional study has been conducted during the period of july-2014 to june-2015 to explore the opinion from key informants of medical education and views from young medical graduates. Data were collected from twenty one in-depth interviewee.

Key informants stressed the necessity of an autonomous constitutional national independent accreditation body, faculty development and teacher evaluation, basic minimum resources in all listed medical colleges.

Study recommended to accelerate the activities to establish national accreditation body for undergraduate medical education which will make way to achieve global accreditation in Bangladesh in coming future.

Key Words: Global accreditation of undergraduate medical education in Bangladesh

\section{Introduction}

Accreditation is official approval given by an authorized organization stating that required standards are achieved in an institution1. The term Accreditation has been used in higher education extensively2.

Undergraduate medical education in many ways is the most important part of the medical education for a country and for a physician3. Accreditation of undergraduate medical education has been practicing worldwide in developed and developing countries4. Fundamental ideas of this program is to ensure incorporation of ongoing global developments, evidence based scientific study and maintenance of basic standards in education for population health and safety. WHO has been addressing for global standards in medical education and global accreditation of medical institutes for long time5. One incompetent health professional can harm an individul in a community but one incompetent medical institute can harm thousands in community. Worldwide many countries have been responded to this call of global accreditation of medical colleges and medical education with their own context and experiencing benefit6.

Worldwide medical institutions are proliferiting. All are



Address of correspondence: Brig. Gen. Suraya Begum

Advisor, Shaheed Ziaur Medical College, Bogra.

E mail: suraiyabegum@ymail.com not maintaing basic standards of medical education specially in developing countries7. Basic standards in medical education was not maintained in the USA a hundred years ago, when Abraham Flxener was appointed by carnegie foundation to standardised the weak medical education of the USA and Canada8. It is the moral duty of the policy makers to make a valid system in medical education which will provide basic or minimum standards of education in both govt. \& non-gov. medical colleges to produce competent medical graduates.

\section{Methodology}

This exploratory cross sectional study has been conducted during the period of july-2014 to june-2015 to explore the opinion from key informants of medical education regarding the need of global accreditation of undergraduate medical education in Bangladesh.

30 key informants were contacted by visiting their offices, email and SMS as applicable and needed. Among them 21 in-depth interview could be conducted. In-depth interview were conducted with advisor to former govt., Member of parliament, Health secretary, Add - health secretary, VC Dhaka university, VC BSMMU, President BM \& DC, Director General DGHS, Director General medical services (Defence), Director medical education, Dean faculty of medicine DU, Trustee Gonoshastho, Director CME, National professor, President BMA, Secretary General BMA, President AME, Principles medical colleges, Senior faculties, Journalist.

Bangladesh Journal of Medical Education 2016;7(2):9-16. (C) 2016 Begum et al., publisher and licensee Association for Medical Education. This is an Open Access article which permits unrestricted non-commercial use, provided the original work is properly cited. 
Necessary permission was taken from concerned authority. Participation were voluntary. Confidentiality, and anonymity of the respondents are maintained.

Data were collected from key informants with in-depth interview. An in-depth interview schedule was prepared according to the objectives of the research and to maintain consistency among interviews. With due prior permission from interviewees interviews were recorded in writing and with voice recorder in most of the cases.

In- depth interview data has been analyzed as guide line given by Pathfinder International guide for qualitative data; available in website (Boyce, Neale 2006, Halcomb, Davidson 2006). Themes were identified and categorized. Data are presented in quotation and in summary form.

\section{Results}

\section{Summary report of in-depth interviews}

After transcription, categorization and condensation summary report of opinions are as follows-

1. There is a great need of a national accreditation body to medical colleges for quality medical education, competent medical graduate and better health service in Bangladesh.

2. National accreditation body must have reflection from global standards. International help may be called upon.

3. There are some overt gaps and lapses in many medical colleges, which need correction with long and short term plans with strong commitment.

4. In this period of globalization medical colleges and undergraduate medical education of Bangloadesh wuld need global accreditation in coming future.

5. Establishing a national accreditation body and planning for global accreditation are direct stimulation for development of medical colleges in Bangladesh.

6. There are shortage of quality and number of faculty specially in basic subjects. A long and short term plans for faculty selection, development and teacher evaluation are very essential.

7. There is a need of policy regarding number of medical colleges to be established and human resource development.

8. Significant number of foreign students especially from SAARC countries as well from the UK and the USA want to have medical education from Bangladesh.

9. There are many direct and indirect advantages of global accreditation. Important one is health service system in Bangladesh will be scaled up.

10. There is no major barrier to work for global accreditation. Collaboration, joint action and high power committee can overcome any obstacle to achieve global accreditation in Bangladesh.

\section{Quotations of key informants}

Conversations were compiled and transcribed verbatim as data as below-

\section{Issue: need of national accreditation}

All the key informants stated that it is very much required.

\section{Quotations}

"National QAS is doing works with some particular objectives, national accreditation body is required for further improvement of undergraduate medical education".

"Accreditation will act as oxygen to us to make up the lapses and gapes in medical colleges. Ministry and others are aware about accreditation of Medical colleges".

"We want uniformity of all medical colleges".

\section{Issue: need of global accreditation}

Most $(n=19)$ of the informants stressed the need of national accreditation first then global accreditation. Two key informants expressed that there is no need of global accreditation

\section{Quotations}

"Yes, we need both national and global accreditation. Our national accreditation will have the basic standards of international level".

"We need more development to get international accreditation".

"National accreditation body would need approval by regional or global organizations".

"This is a system of capitalism and will impose brain drain from Bangladesh".

Many medical graduates are doing odd jobs in abroad".

Issue: 'global standards for undergraduate medical education' given by World Health Organization (WHO) /World Federation for Medical Education (WFME).

majority ( $\mathrm{n}=12$ ) of the respondents welcomed the guide line and expressed the need of tailoring of it.

Issue: enrollment of name of Bangladesh medical colleges in WHO Directory of Medical school.

majority $(n=14)$ of the key informants stated that it is not important now and would be considered in coming future. but one of the quote was-

"It is important for Bangladesh to enlist name of medical colleges WHO directory. This listing of names need processing through ministry. It is necessary for coming future".

\section{Issue: expected benefits having global accreditation.}

most $(n=20)$ of the informants gave statements about many benefits. 


\section{Quotations}

"There would be many direct and indirect benefits of having global accreditation in Bangladesh”.

"Medical Graduates will provide service confidently at home and in abroad, they will not do odd jobs in abroad".

\section{Issue: anticipated barriers to get Global Accreditation.} majority $(n=16)$ of the key informants believed that there would no barriers, no big challenges if the work is done jointly and with 'goodwill'.

\section{Quotes}

"Motivation and understanding might need time".

"We need to have a service mentality. Many are busy with personal development, but national development needs to be highlighted".

While talking about present activities of medical education key informants stated following views-

Issue: general perception about 'standards' of undergraduate medical education in Bangladesh.

majority $(n=16)$ of the respondents stated, though some of medical colleges are doing well, but in general standards are not satisfactory in many aspects. Many medical colleges are lacking basic requirements. There are gross variation amongst government, non-government, old and new medical colleges in Bangladesh.

Quotes are as follows-

"In general we cannot say standards are good. There are wide gaps between Dhaka medical college and Pabna medical college. There is no basic uniformity amongst medical colleges".

Issue: dissemination of mission and outcomes of medical colleges.

Majority $(n=12)$ of the key informants stated that in new curriculum mission and outcomes of medical colleges and graduates are expressed in formal way.

\section{Quotations}

"It is practiced in informal way and BM\&DC needs to stress on it and instructs on it".

"There are some non-academic mission like social, pride, prestige, commercial in establishing a medical college".

"In a low income country here everybody is working for self sufficiency or well off”.

"In Armed Forces Medical College (AFMC); course starts one month before government schedule to provide orientation about the course including ethics and english. Guardian are also called to know and to give opinions".

\section{Issue: students selection criteria}

Majority of the key informants $(n=17)$ appreciated the present qualifying marks in written admission test and stated that it is a milestone in undergraduate medical education in Bangladesh. Key informants expected to have test for attitude, aptitude, capability and desirability of candidates to carry out the very stress full and complex medical learning.

\section{Quotations}

"Only merit is considered. District quota and tribal quota are nonfunctional. Attitude, aptitude, capability and desirability are important”.

"For rural retention of doctor we are thinking new ways".

"We have to maintain the standard of questions, and must stop the question leaking”.

"We have achieved a good admission system and will achieve everything".

\section{Issue: students' support systems}

Majority $(n=14)$ of the respondents claimed that informally and inadequately students' support system is practiced. Some key informants expected the need of students' loan system and extended students' support system.

\section{Quotation}

"In the context of Bangladesh where gross national income is low, for many student it is difficult to carry on the expenses of medical education. In Dhaka medical college there are many poor students".

"They need direct and indirect guide, supports other than organized classes".

"There are absolute free quota for meritorious students in non-govt. medical colleges".

\section{Issue: teaching and learning activities.}

majority $(n=15)$ of the key informants claimed that teaching and learning activities are not satisfactory in all medical colleges.

\section{Quotations}

"Teaching must be objective based. It is not possible for students to learn everything what a teacher knows".

"In government sector many teachers do not go to posting place. More over private practice is a major factor for it. Community based teaching has become paper work not real".

"Evening clinical teaching, supervision of clinical teaching, bedside teaching, ethics are not practicing properly in many cases. Resources for bed side teaching are poor in many situations".

"Only bookish knowledge is not sufficient; social science, behavioral science, mentality, ethics, doctor patient relationship, empathy, communication are very important and to be taught and learnt in medical colleges".

"Scientific teacher student ratio is essential".

Issue: assessment and students' performance.

few $(n=7)$ of the key informants claimed that in general students' assessment is rightly measuring students' performances though there are some lapses and gapes.

\section{Quotations}

"Assessment tools have been developed structured and organized in last many years. But practical uses of those tools in assessment are not up to the expectation".

"Biased scoring in written and oral assessment are observed

Bangladesh Journal of Medical Education 2016;7(2):9-16. 
and more in non- government medical colleges. In some cases 'pass' is graced by the teachers, not earned by the students".

"There should be fifty percent marks in formative assessment".

\section{Quotations}

"Assessment tools have been developed structured and organized in last many years. But practical uses of those tools in assessment are not up to the expectation".

"Biased scoring in written and oral assessment are observed and more in non-government medical colleges. In some cases 'pass' is graced by the teachers, not earned by the students".

"There should be fifty percent marks in formative assessment".

Issue: teacher selection/intake \& faculty development. majority $(n=14)$ key informants mentioned that faculty selection and development are not going on rightly. Most of the informants repeatedly stressed the need of CME program like, workshop, training, medical education course, seminar, research, scientific paper presentation, for all teachers. Teachers must read latest books and must not go for any obsolete question.

\section{Quotes}

"Large number of faculty are young lecturers. Students spend a lot of time with them. Lecturers need to know the art of teaching. Teachers' teaching quality, making understood to students, dedication to teaching are important".

"Weakness in teachers will produce weak graduates. Teacher evaluation system is needed"

"Teacher selection should follow the criteria of BUET and University. In whole world teacher selection is done by University".

\section{Issue: adequacy of resources in medical colleges.}

Some $(n=4)$ of the key informants claimed resources are adequate evel

in the context of Bangladesh.

Quotations are as follows -

"In many places medical college is made over old small clinic in a market, no separate building for hospital".

"Patients are scarce for bed side teaching and learning".

"There are lack of modern instructional material, and lack of information technology for teachers and students.

\section{Issue: use of available resources in best possible way.}

All $(n=21)$ the key informants commented that available resources are not used in best possible way. Many costly equipments are not used, repaired and maintained properly. Teacher distribution and ranking are biased and defective. Somewhere justice is lacking. Research and publications in clinical side are limited. There are some personal publications only.

Quotations are as follows -

"Medical colleges should be made autonomous for posting of teachers. Political factor plays a good role."

"Research fund is low in comparison to neighboring countries".

Issue: monitoring, evaluation and implementation of educational program.

Most $(n=16)$ of the key informants expressed that in undergraduate medical education monitoring, evaluation and implementation of educational program have not been adequate nor timely.

\section{Quotations}

"Quality Assurance Scheme does not work regularly and does not report all facts. Reports are in paper not in sprit. Pair medical colleges are not working formally in many situations".

"Only financial monitoring is functional".

"Data collection system is weak, corrections and implementations are weaker".

Issue: administration and management of medical colleges.

To run a medical college administration and management has a great role, emphasized by majority $(n=16)$ of the key informants and which is not satisfactory in many medical colleges at present.

\section{Quotations}

"There are organized courses for management and administration".

"Administration in many cases are not interested in educational activities. They are interested in 'result' only. Qualified staff sometimes does not get proper posting".

\section{Issue: renewal and updating of educational program.}

most $(n=19)$ of the respondents expressed that renewal and updating in educational program are neither adequate nor timely even in the context of Bangladesh.

\section{Quotes}

"There is need of more renewal and updating about national and international health problems, management of climate change, management of rapid urbanization, natural disaster, and mass casualties".

Others: additional quotes are as follows -

One of the important key informants advised to quote the following statements:

"Primary and secondary education have great role in higher education In many developed countries primary and secondary education are conducted by PhD holder".

Bangladesh Journal of Medical Education 2016;7(2):9-16. 


\begin{abstract}
"Bangladesh needs a licensing examination for medical graduates before starting independent clinical practice".
\end{abstract}

"Medical college should be established according plan, because teachers are not purchasable overnight".

\section{Discussion}

Present trends in higher education are standardization, quality assurance, internationalization, virtualization, privatization and accreditation'.

Well known medical education quality assurance and quality control took place during in the year of 1910 . Worldwide known and reliable medical accreditation systems are General Medical Council (GMC); UK ${ }^{10}$, Liaison Committee on Medical Education (LCME) ; USA ${ }^{11}$. They are working for many years in their countries and proved to be essential for medical education.

WHO has intensified its efforts in basic medical education and has collaborated with a number of organizations at both global and regional levels to carry out activities aimed at improving human resources for health through better quality education ${ }^{3}$. The key component of this global collaboration was the adoption of 'international standards' in basic medical education and global accreditation of medical schools ${ }^{12}$.

In Bangladesh quality assurance of MBBS course is contributing by BM\&DC, National Quality Assurance Body, Deans of faculty of medicine of universities, Ministry of Health and Family Welfare, Institutional Quality Assurance13. No formal accreditation body, yet. Ministry of Health and Family Welfare has been proposing for an national accreditation body which is under way for development and implementation ${ }^{14}$.

Results of this study showed that key informants highly stressed the need of an independent, fair, effective national accreditation body to maintain the quality of all medical colleges and medical education in Bangladesh. They also stressed that national accreditation body must have reflection of global accreditation to maintain the basic global standards in medical education in Bangladesh. It is high time to give emphasis to achieve national, regional and international accreditation of each and individual medical colleges of Bangladesh.

The concept of quality medical education and global accreditation of medical college started in Bangladesh in early 1980's. That time Dhaka medical college applied for accreditation from GMC of UK and Dhaka medical college attained that accreditation in ${ }^{15}$. Such activities give evidence that need of global accreditation of medical education of Bangladesh had been felt since long time.

Prihatiningsih describes, Further Improvement of Medical Colleges (FIMC) project in Bangladesh recognized that Quality Assurance Scheme was required for achievement and sustainability of desired standards of medical education. International organizations played a great role in it's development $1^{6}$.
The core of the undergraduate medical curriculum consist of the fundamental theories and practices of medicine, specifically basic bio-medical, behavioural and social sciences, general clinical skill, clinical decision skill, communication skill and medical ethics, which must be addressed by all medical institutions aiming to produce safe and quality medical graduate. These elements have an important bearing on the concept of international standards in medical education ${ }^{6}$. The task of medical education is to provide health care $^{18}$. Though worldwide there are some difference in socio- economic, cultural, health and disease spectrum but there are many similarities in structure, process and product of medical institutes also.

Violations of standards or absence of standards in medical education are identified worldwide and such evidence are also stated by key informants of this study.

In-depth interview (IDI) result of this study highly stressed the very need of human factors like- behavioural science, social science, serving attitude ethics, clinical skill and leadership in medical education and in Bangladesh.

Sweart who worked for FIMC project in Bangladesh states quality doctors deliver quality health care, thus the focus should be on both the process of the undergraduate medical education and the product of the undergraduate medical education. Accreditation and quality assurance scheme of medical institute ensure quality medical graduates ${ }^{19}$.

Majumder states higher authority in Bangladesh is always concerned about physicians and their service and not about the availability of standards medical education. Lack of qualified teaching staff and resources are important identified problems in undergraduate medical education of Bangladesh $^{20}$.

Amin, Burdick report there are challenges, opportunity and diversity in medical education in South Asia. Weak regulation, growth of medical colleges, ineffectual accreditation process, admission practice, stagnant curricula, antiquated emphasis on rote learning method, inadequate clinical exposure specially in new medical colleges, dubious assessment practice, shortage of qualified faculty, national corruption, historical past socio-political structure, economic advancement are the studied challenges in medical education in South Asia ${ }^{20}$.

There are many essential factors needed to make the medical education successful; absence of those factors will lead to failure of educational program even in the presence of meritorious students.

Cueto J J, Burch V C, Adnan N A state 'Accreditation of undergraduate medical training programs: practices in nine developing countries are similar that is present in the United States'. Argentina, India, Kenya, Malaysia, Mongolia, Nigeria, Pakistan, Philippines and South Africa were the studied countries ${ }^{4}$.

Bangladesh Journal of Medical Education 2016;7(2):9-16. 
Yahya (2013) states; medical education in South-East Asia has also experienced many changes and challenges over the last few years. WFME global standards can be used to compare the standards of any medical college for development; specially in South-East Asia ${ }^{21}$.

Ahmed, Elzien (2007) studied the use of WFME standards. Study states : WFME standards are considered an essential mean for assessing and developing undergraduate medical education in developing countries ${ }^{22}$.

These two studies give evidence that Bangladesh can pilot the WFME global standards in undergraduate medical education.

Van Zanten M, McKinley D and et al (2012a) studied the value of medical school accreditation on students' outcomes, in the countries of Mexico and the Philippines medical graduates who voluntarily take part in the United States Medical Licensing Examination (USMLE). Result showed better performance of students form accredited schools ${ }^{23}$.

In British colonial time Calcutta Medical College and Dhaka Medical College were established to serve the military people (WHO 2012). Now medical colleges in Bangladesh are established to serve the population in Bangladesh. Use of global accreditation in undergraduate medical education will benefit the people of Bangladesh.

Alexner Flexner visited 155 medical schools of the USA and Canada himself and published his report in 2 years (1908-1910) in 1910 $0^{\text {flexner report1910 }}$. That 2 years investment has given a world class standardization of medical education in the USA and Canada for the next 100 years and more. It is possible that proposed national accreditation body of undergraduate medical education in Bangladesh would give same result for about 98 medical colleges of Bangladesh. It is an opportunity to improve the quality of undergraduate medical education by using this instrument, 'Global Standards'.

WFME states it is working for the whole world; for those who already have and do not have own standards in medical education. Any country can use WFME global standards. WFME basic medical education standards was first suggested in 1998, then they were piloted in a number of medical schools in all 6 WHO regions ${ }^{18}$.

WFME has mentioned there are many advantages global standards of undergraduate medical education. ${ }^{6}$. It is a template, a guide, a lever, blue print to develop and to improve undergraduate medical education worldwide. Since 1998 to 2012 this global standards has been prepared and revised by many experts from six regional areas of WHO covering the whole world; with evaluation and adjustment of standards. Use of WFME global standards will give overall view about development and continuous improvement of undergraduate medical education. WFME global standards has given guide lines for better planning and better organization for medical colleges, better teacher selection and faculty development, better students selection at admission, better student assessment in course, better utilization of available resources. Use of global standards will ensure responsibility and accountability of teachers; students; and staff. Use of global standards will save money and time to making a new standards, it's use will earn fund from donor for institution. Use of global standard will provide qualified health workforce to community, better health in a country. It will ensure patient safety, will decrease abroad treatment of patient and will save money. It will increase foreign students study in a country and many more. As this is an exploratory study with small sample size numerical result is not highlighted.

Key informants mentioned there would be many direct and indirect benefits of global accreditation in medical education in Bangladesh. Important one is, population of Bangladesh will get better health service. Patient safety will increase; complaints against doctors will decrease and less people will go abroad for treatment. This will decrease the expenses on health. Medical graduates will get value, honor and job in the world, even in the developed countries. Medical graduates from accredited institution will improve health indicators to make Bangladesh a developed country.

This study has also looked for probable barrier to implement global standards in undergraduate medical education in Bangladesh. Key informants also stressed that there is no major barrier to work for global accreditation in Bangladesh. Collaboration, joint action and high power committee can overcome any obstacle to achieving global accreditation in Bangladesh.

IMED in September 2014, states that there are 2,409 recognized and operating medical schools in 180 countries or territories listed in the International Medical Education Directory (IMED). The medical schools listed in IMED are recognized by the appropriate government agencies in the countries where the schools are located.

World Bank states that there are four identified broad factors for success in any project $t^{24}$. They are-

- consistent commitment

- consideration underlying constraints

- flexibility in the implementation of the project,

- encouragement and support for institutional

For planning and implementation of national and global accreditation in medical education in Bangladesh World Bank design would be appropriate and a good guide.

\section{Conclusion}

WHO has given a definition of human Health, call for health for all. WHO and other medical educational organizations have evidences that global standards and global accreditation are essential for consistence in medical education world wide to achieve peoples' health. This study results showed there is a great need of a national accreditation are essential for

Bangladesh Journal of Medical Education 2016;7(2):9-16. 
consistence in medical education world wide to achieve peoples' health. This study results showed there is a great need of a national accreditation body to medical colleges for quality medical education, national accreditation body must have reflection from global standards to produce competent and competent doctors in Bangladesh to provide desirable health service in Bangladesh.

Study recommended to accelerate the activities to establish national accreditation body for undergraduate medical education which will make way to achieve global accreditation in Bangladesh in coming future.

\section{Acknowledgement}

I would to express my gratitude to Professor Dr. Md. Humayan Kabir Talukder professor of Curriculum Development \& Evaluation \& Professor Dr. AFM Saiful Islam Director CME for their guidance; suggestions and encouragement. I would like to thank Brig Gen Md Ahasan Habib for his valuable inputs and correction. I am extremely grateful to all key informants and young graduates for their kind participation.

\section{References}

1. Wikipedia. Educational accreditation. In Internet; 2015. visited on 04-08- 2015 with en.wikipedia.org/ wiki/Educational.

2. Eaton S. Judith. The value of accreditation 'letter from president-2003'Council for Higher education accreditation (CHEA): Washington DC.2003. www.chea.org/pdf/pres-ltr-value-accrd-5- 03.pdf; visited on 01-02-2015.

3. Schwarz R M, Wojtczak A. Global minimum essential requirements: A road towards competence-oriented medical education. Medical Teacher. 2002; 24(2): 1259

4. Cueto JJ, Burch VC, Adnan NA, Afolabi BB, Ismail Z, Jafri W, et al. Accreditation of undergraduate medical training programs: practices in nine developing countries as compared with the United States. Abingdon. Education for Health. 2006; 19(2):207-222.

5. WHO/ECFMG. Towards a global consensus on quality medical education: serving the needs of population and individuals. Proceedings of the 1994 WHO/ ECFMG Consultation in Geneva. Academic Medicine.1995; 70(7), Suppl.

6. WFME. Basic Medical Education WFME Global Standards for Quality Improvement. Denmark. World Federation for Medical Education. 2012. www.wfme.org;visited on 05-05-2015.

7. Karle H. Relevance of the WFME global standards in medical education to the South East Asian region. South East Asian Journal of Medical Education. 2007; Inaugural issue: 2-7.

8. Flexner A. Medical Education in the United States and Canada, A report to the Carnegie Foundation for the
Advancement of Teaching. Carnegie Foundation: New York. Bulletin no 4.1910; P:346

9. Karle H. Second Policy Dialogue on Human Resources for Health. Presentation in Vilnius Conference. World Federation for Medical Education. 2005. http://www.wfme.org; visited on 06-05-2014.

10. GMC. Tomorrow's Doctors. Recommendations on undergraduate medical education. The Education Committee of the General Medical Council: London. 1993.

11. LCME . LCME Accreditation Guidelines for New and Developing Medical School. Liaison Committee on Medical Education. Association of American Medical Colleges: Washington DC.2008. www.lcme.org; visited on 12-12-2014.

12. WHO/WFME. Accreditation of medical education institutions. WHO-WFME Task Force on Accreditation. Geneva. World Health Organization / World Federation for Medical Education. 2005. www.wfme.org, ISBN 92 4159273 7; visited on 12-01-2015.

13. DGHS, CME. National Guidelines and tools for quality Assurance Scheme (QAS) for Medical Colleges in Bangladesh. Dhaka: NQAB ; 2012.

14. DGHS 2014. Health Bulletin. Management Information System; Directorate General of Health Services. Mohakhali: Dhaka 1212 www.dghs.gov.

15. MoHFW. Letter for Accreditation Committee, Medical College. Letter no-Medical Education-2/Miscellenious8/513, Bangladesh: MoHFW; 2014.

16. Islam T. Report on Dhaka Medical College. In internet; 2010. visited on 2-2-2015 through http://www. assignmentpoint.com/science/medical/report-ondhaka-medical-college.htm.

17. Prihatiningsih T S. Quality Assurance In Undergraduate Medical Education: The Bangladesh Experience. Journal Manajemen Pelayanan Kesehatan.2003; 6 (4):237-49.

18. Karle H, Walton H, Lindgren S. The World Federation For Medical Education. History of The First Forty Years 1972-2012. World Federation for Medical Education: Copenhagen. 2012; P:30. http://www.wfme.org; visited on 06-05-2014.

19. Majumder M A. Medical Education in Bangladesh: Past Successes, Future Challenges. Bangladesh Med J. 2003; 32:37-9. www.academia.edu; visited on 14-08-2014.

20. Stewart A. Quality Assurance and Accreditation: Where Do They Meet? Towards Unity for Health; World Health Organization. 2000; 0 (1):35-6.

21. Amin Z, Merrylees N, Hanif A, Talukder M H K . Medical education in Bangladesh. Medical Teacher. 2008;30: 2437.

Bangladesh Journal of Medical Education 2016;7(2):9-16. 
22. Ahmed H A, Elzien A. Global Standards in Basic Medical Education Are they suitable for Accreditation of Schools of Medicine in Developing Countries? Sudanes Journal of paediatrics. 2007; 8: 48-65.

23. Yahya S. WFME Standards for Educational Programs: Tutors' Perceptions in

24. Pakistan. Education in Medicine Journal. 2013; 5(1P): 45-53. www.eduimed.com.
24. van Zanten M, McKinley D, Montiel I D \& Pijano C V. Medical education accreditation in Mexico and the Philipines: impact on student outcome. Medical Education. 2012; 46:586-592. doi:10.1111/j.13652923.2011.04212.x; visited on 23-12-2014.

25. World Bank . Successful projects. Health Nutrition and Population Strategy. New York. 1999. 